like it -fall somewhat across the diagnostic boundaries lying between genuine eosinophilic leukaemia, and eosinophilic collagen disease. These two conditions may be extremes of a single spectrum caused by a basic single underlying cause as yet unknown. We would propose that a descriptive title should be used to avoid unintentional categorization, such as idiopathic eosinophilic leukaemoid reaction. The relation of the terminal diffuse intravascular thrombotic process to the initial disease process is obscure.

The role, if any, of the intracellular virus-like particle, seen only in the nucleus of one eosinophil is quite unknown. There were no pathological features of encephalitis. As there was no lymphatic vasculitis, one cannot postulate that a sensitivity reaction occurring between the agent and antibodies against it was causing local fibrin deposition and intra-vascular coagulation. It may be present in the similar uncertain role played by the polyoma virus in the progressive multifocal leukoencephalopathy seen associated with Hodgkin's disease. We feel unjustified in drawing any conclusions on the strength of one isolated observation.

\section{Acknowledgment}

We should like to thank Dr C. D. R. Pengelly, Consultant Physician at Altrincham General Hospital, for referring this patient.

\section{References}

Bentley, H.P., Reardon, A.E., Knoedler, J.P. \& Krivit, W. (1961) Eosinophilic leukaemia; report of a case with review and classification. The American Journal of Medicine, 30, 310.

De Gruchy, G.C. (1970) Clinical Haematology in Medical Practice, p. 456. Third Edition. Blackwell Scientific Publications, Oxford.

ENgfeldt, B. \& Zetterström, R. (1956) Disseminated eosinophilic collagen disease. A clinical and pathological study of a clinical entity related to Loeffler's syndrome. Acta Medica Scandinavica, 153 (5), 337.

Faddell, E.J., Crone, R.I., Leonard, M.E. \& Altamirano, M.D. (1957) Eosinophilic leukaemia. Archives of Internal Medicine, 99, 819.

Gardner-Thorpe, C., Harriman, D.G.F., Parsons, M. \& Rudge, P. (1971) Loeffler's eosinophilic endocarditis with Balint's syndrome (optic ataxia and paralysis of visual fixation). Quarterly Journal of Medicine, 158, 249.

Nordlander, N.B. (1951) Eosinophilic leukaemia infiltrating the gasserian ganglion. Acta Medica Scandinavica, 139 (2), 146 .

ODEBerg, B. (1965) Eosinophilic leukaemia and disseminated eosinophilic collagen disease - a disease entity. Acta Medica Scandinavica, 177, 129.

Rickles, F.R. \& Miller, D.R. (1972) Eosinophilic leukaemoid reactions. Report of a case and its relationship to eosinophilic leukaemia and review of the paediatric literature. Journal of Paediatrics, 80, 418.

\title{
Treatment of pulmonary tuberculosis in a patient on maintenance haemodialysis
}

\author{
F. W. SMITH \\ M.B., Ch.B. \\ Medical Renal Unit, Aberdeen Royal Infirmary
}

\author{
G. R. D. CAtTo \\ M.B., M.R.C.P.(U.K.) \\ University of Aberdeen
}

\author{
M. MACLeOD \\ M.D., F.R.C.P.E. \\ University of Aberdeen
}

\begin{abstract}
Summary
A case of pulmonary tuberculosis in a patient on maintenance haemodialysis is reported. A 37-year-old man who had received intermittent haemodialysis for 5 years, developed pulmonary tuberculosis which was treated initially with isoniazid, sodium aminosalicylate (PAS) and rifampicin. Isoniazid and PAS were discontinued and treatment continued with rifampicin alone. One year later, the patient is well, has no evidence of active tuberculosis and undertakes his own dialysis at home.
\end{abstract}

\section{Introduction}

Pulmonary tuberculosis is a serious and not uncommon complication of chronic renal failure treated by maintenance haemodialysis (Brunner et al., 1972). Adequate therapy for the condition is difficult to assess clinically as the major therapeutic agents, including streptomycin, sodium aminosalicylate (PAS), isoniazid and ethambutol, are normally excreted in the urine (Welch, 1954) and produce important toxic effects if blood levels become elevated. Thus, in oliguric or anuric patients, safe and effective 
therapy is possible only when the blood levels of these drugs are routinely measured.

Rifampicin, however, is excreted in the bile and does not accumulate in the serum of anuric patients (Spring, 1968). The value of this drug in the treatment of pulmonary tuberculosis in a patient on maintenance haemodialysis is illustrated in the following case report.

\section{Case report}

Mr W. R., a 37-year-old electrician with chronic glomerulonephritis, was started on maintenance haemodialysis in April 1967. He was dialysed for 14 hr twice weekly on a flat bed dialyser with a surface area of $1 \mathrm{~m}^{2}$ and remained well for 5 years; then he developed a non-productive cough with increasing dyspnoea. Despite repeated investigations, no diagnosis was made at this time but in June 1972 a chest radiograph revealed patchy, ill-defined areas of consolidation (Fig. 1) and acid-fast bacilli were demonstrated in the sputum. M. tuberculosis was subsequently cultured. Haemodialysis treatment was increased to $10 \mathrm{hr}$ thrice weekly and therapy was started with isoniazid $200 \mathrm{mg}$ and PAS $8 \mathrm{~g}$ as Pasinah-D and rifampicin $600 \mathrm{mg}$ daily. Blood levels of PAS, measured $8 \mathrm{hr}$ after the administration of the drug by a modification of the method of Bratton and Marshall (1939) varied between $8 \mathrm{mg} / 100 \mathrm{ml}$ and 10

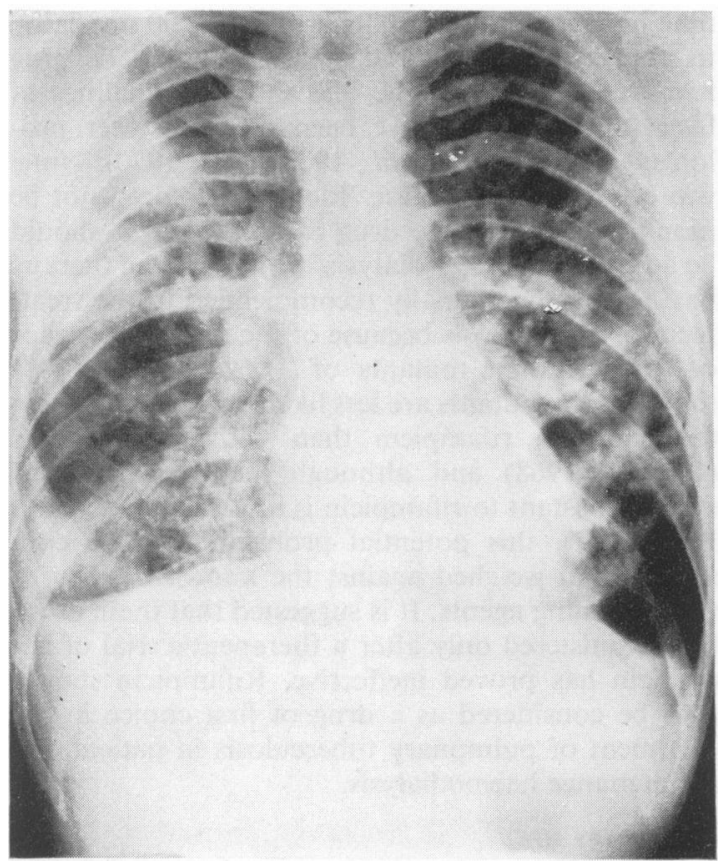

FIG. 1. Chest radiograph showing patchy, ill-defined areas of consolidation. $\mathrm{mg} / 100 \mathrm{ml}$; this exceeds the therapeutic range defined by Emerson and Kuper (1964). PAS dosage was accordingly reduced to $4.5 \mathrm{~g}$ daily and satisfactory serum levels of between $2 \mathrm{mg} / 100 \mathrm{ml}$ and 4.5 $\mathrm{mg} / 100 \mathrm{ml}$ before dialysis were recorded. Serum rifampicin levels measured before dialysis by a bioassay method using Sarcina lutea as the test organism (Jeannes, Jessamine and Eidus, 1972) were between $3.75 \mu \mathrm{g} / \mathrm{ml}$ and $4 \mu \mathrm{g} / \mathrm{ml}$ and thus were within the therapeutic range (Spring, 1968).

The $M$. tuberculosis cultured from the sputum was shown in vitro to be sensitive to all the commonly prescribed agents but was particularly sensitive to rifampicin. Two months after commencing treatment, the patient developed severe diarrhoea, PAS and isoniazid were withdrawn, treatment was continued with rifampicin alone and the diarrhoea gradually improved. As the reintroduction of PAS coincided with a further exacerbation of the gastrointestinal symptoms, treatment with this drug was finally discontinued and the patient experienced no further bowel upset. At this time, however, a pericardial effusion was detected (Fig. 2) and the patient's condition deteriorated. This effusion was considered to be tuberculous, not uraemic in origin, as the blood urea levels before dialysis did not exceed $177 \mathrm{mg} / 100$ $\mathrm{ml}$. Despite the relatively short duration of therapy, the possibility of a drug-induced lupus syndrome produced by either isoniazid or PAS was considered

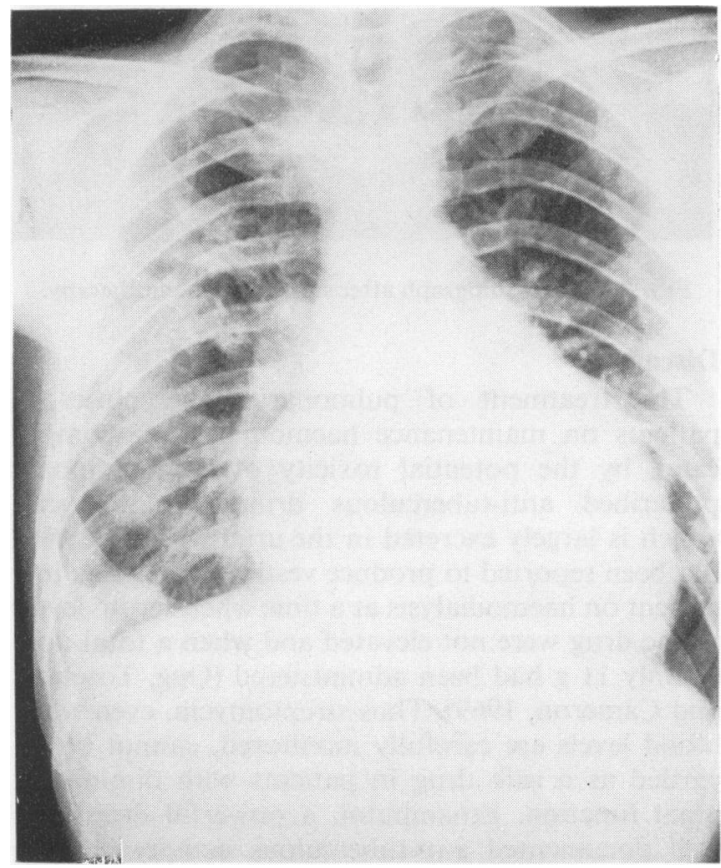

FIG. 2. Chest radiograph showing pericardial effusion. 
(Alarcon-Segovia, 1969). However, LE cells were not detected in the peripheral blood and the antinuclear factor was consistently negative. During the following 2 months the effusion began to diminish and 7 months after starting anti-tuberculous therapy the patient was able to start training for home dialysis. He remains well; his chest X-ray has returned almost to normal (Fig. 3) and acid-fast bacilli have not been isolated from the sputum during the past 12 months. The patient now undertakes his own haemodialysis at home thrice weekly and continues on rifampicin $450 \mathrm{mg}$ daily.

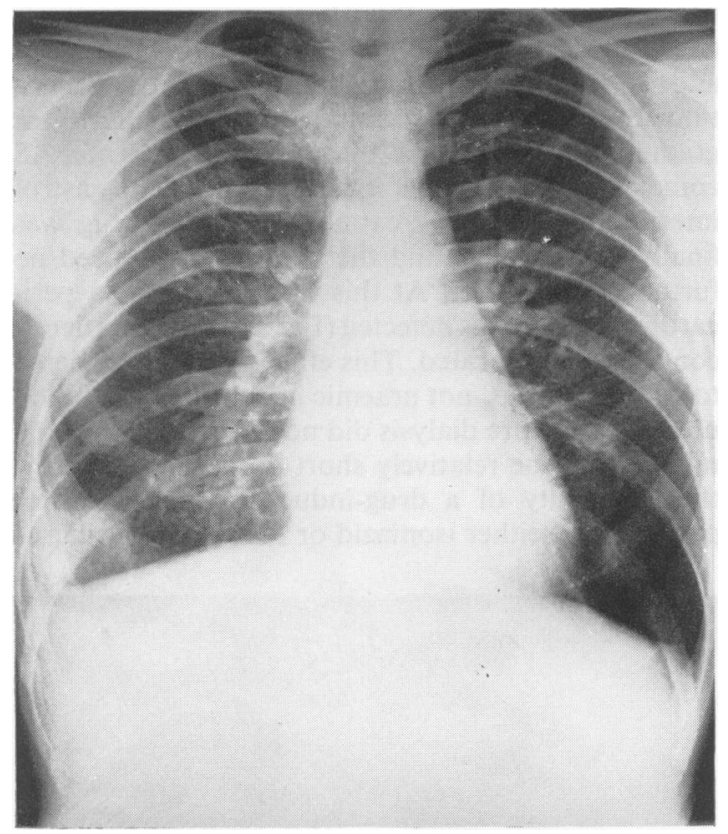

FIG. 3. Chest radiograph after successful chemotherapy.

\section{Discussion}

The treatment of pulmonary tuberculosis in patients on maintenance haemodialysis is complicated by the potential toxicity of the commonly prescribed anti-tuberculous drugs. Streptomycin, which is largely excreted in the urine (Welch, 1954), has been reported to produce vestibular damage in a patient on haemodialysis at a time when serum levels of the drug were not elevated and when a total dose of only $11 \mathrm{~g}$ had been administered (Ogg, Toseland and Cameron, 1969). Thus streptomycin, even when blood levels are carefully monitored, cannot be regarded as a safe drug in patients with diminished renal function. Ethambutol, a powerful drug with well documented anti-tuberculous activity both in vitro and in vivo has been widely used in the treatment of pulmonary tuberculosis in recent years.
Retrobulbar neuritis and visual impairment are, however, not infrequent side effects of therapy (Garrod and O'Grady, 1971); indeed it has been suggested (Wechsler, 1971) that not only should blood levels of the drug be monitored routinely but also that all patients should have complete eye examinations before and during treatment. As excretion is by the kidneys (Wechsler, 1971), ethambutol may not be administered with safety to patients with renal failure.

Isoniazid is only partially excreted in the urine and thus an accumulation of potentially toxic metabolites which cannot be monitored is an importan possibility (Ogg et al., 1969): generalized seizures have been reported following isoniazid therapy for tuberculosis in a patient with uraemia (Aach and Kissane, 1972). It has been suggested recently that the acetylation phenotype of the individual is more important than renal function in determining the serum halflife of isoniazid (Bowersox et al., 1973). However, as the phenotype cannot be definitely established in patients with renal failure, these patients should be considered to be 'slow acetylators' and the dose of isoniazid reduced accordingly (Bowersox et al., 1973). PAS, however, although not a potent drug, is excreted mainly by the kidneys, and is an acceptablg therapy, provided that the daily dosage is reduce and blood levels routinely monitored (Ogg et alôे. 1969).

Rifampicin has none of these toxic effects and may be given in normal dosages (450-600 mg daily) to patients with impaired renal function. The drug is excreted mainly in the bile and abnormalities of liver function tests have been reported after prolonged use (Jeannes et al., 1972; Lees, 1970). None was observed in this case. Blood levels need not be monitored but, as the drug is dialysable, it should be administered after dialysis. Multiple drug therapy has been conventionally recommended in the treatment of tuberculosis because of the rapid emergence of drug-resistant mutants of $M$. tuberculosis. Although such mutants are less likely to develop during therapy with rifampicin than with other agents 옹 (Canetti, 1968) and although the proportion of $\supset$ strains resistant to rifampicin is low (Grumbach and Rist, 1967), this potential problem must be con-

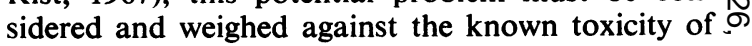
the remaining agents. It is suggested that these drugs $N$ be administered only after a therapeutic trial of rif- స్ట ampicin has proved ineffective. Rifampicin should 0 thus be considered as a drug of first choice in the treatment of pulmonary tuberculosis in patients on $\frac{\mathbb{D}}{\mathscr{C}}$ maintenance haemodialysis.

\section{References}

AACH, R. \& KisSANE, J. (1972) Generalized seizures following isoniazid therapy for tuberculosis in a patient with uraemia. American Journal of Medicine, 53, 765. 
Alarcon-Segovia, D. (1969) Drug induced lupus syndromes. Mayo Clinic Proceedings, 44, 664.

Bowersox, D.W., Winterbauer, R.H., Stewart, G.I., ORME, B. \& BARRON, E. (1973) Isoniazid dosage in patients with renal failure. New England Journal of Medicine, 289, 84.

Bratton, A.L. \& Marshall, E.K. (1939) New coupling component for sulphanilamide determination. Journal of Biological Chemistry, 128, 537.

Brunner, F.P., Gurland, H.J., Harlen, H., Schoner, K. \& PARSONS, F.M. (1972) Combined report on regular dialysis and transplantation in Europe II. Proceedings of the Ninth Congress of the European Dialysis and Transplant Association, p. 3. Pitman Press, Bath.

CANetti, G. (1968) Some comparative aspects of rifampicin and isoniazid. Tubercle, 49, 367.

EMERSON, P.A. \& KuPER, S.W.A. (1964) PAS serum concentrations obtained with an adegrate granule preparation of PAS and isoniazid. Tubercle, 45, 276.

Garrod, L.P. \& O'Grady, F. (1971) In: Antibiotic and Chemotherapy. Livingstone, Edinburgh and London.
Grumbach, F. \& Rist, N. (1967) Experimental anti-tuberculous activity of rifampicin, derivative of rifampicin SV. Revue de la Tuberculose, 31, 749.

Jeannes, C.W.L., Jessamine, A.G. \& Eidus, L. (1972) Treatment of chronic drug resistant pulmonary tuberculosis with rifampicin and ethambutol. Canadian Medical Association Journal, 106, 884.

LEES, A.W. (1970) Jaundice with rifampicin treatment. British Journal of the Diseases of the Chest, 64, 90.

Ogg, C.S., Toseland, P.A. \& Cameron, J.S. (1969) Pulmonary tuberculosis in a patient on intermittent haemodialysis. British Medical Journal, 2, 283.

SPRING, P. (1968) The pharmacokinetics of rimactane in patients with impaired liver and kidney function. Symposium on Rimactane, p. 32. Ciba, Basle.

WECHSLER, H. (1971) Renal tuberculosis. In: Diseases of the Kidney (Ed. by M. B. Strauss and L. G. Walt). Little, Brown \& Co., Boston.

Welch, H. (1954) Principles and practice of antibiotic therapy. In: Antibiotics Annual 1954-55 (Ed. by H. Welch and F. Marti-Ibanex), p. 103. Medical Encyclopaedias Incorporated, New York. 